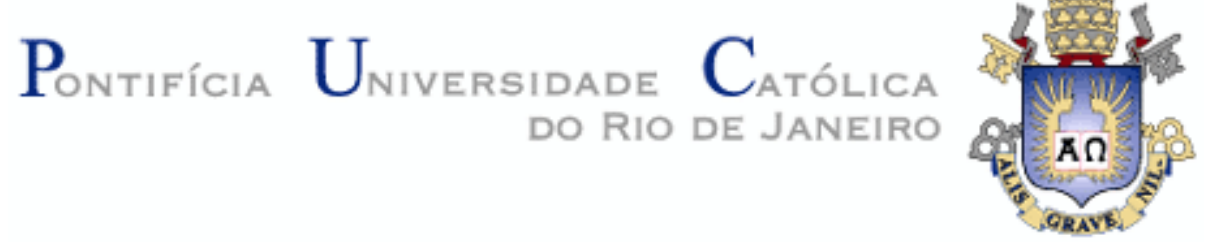

Andreza de Lima Ribeiro Teixeira

DEGAS e a FOTOGRAFIA:

A (re)invenção do olhar

\begin{abstract}
Tese de Doutorado
Tese apresentada ao Programa de Pós-graduação em História Social da Cultura como requisito parcial para obtenção do grau de Doutor em História Social da Cultura.
\end{abstract}

Orientador: Prof. Ronaldo Brito Fernandes

Rio de Janeiro

Março de 2018 


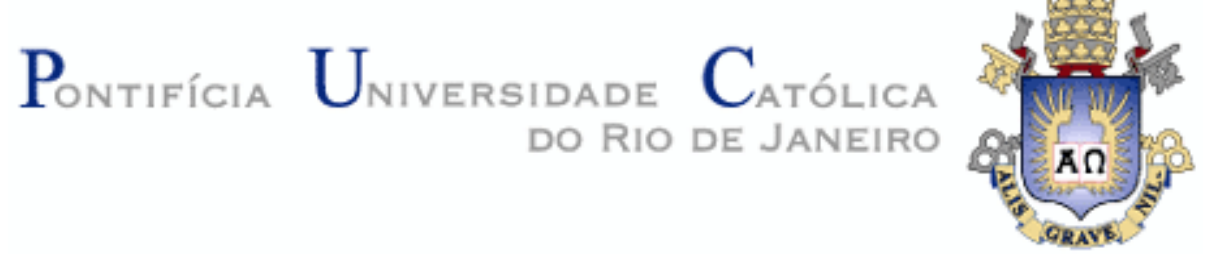

Andreza de Lima Ribeiro Teixeira

\section{Degas e a fotografia: a (re)invenção do olhar}

Tese apresentada como requisito parcial para obtenção do grau de Doutor pelo Programa de PósGraduação em História Social da Cultura do Departamento de História do Centro de Ciências Sociais da PUC-Rio. Aprovada pela Comissão Examinadora abaixo assinada.

Prof. Ronaldo Brito Fernandes Orientador

Departamento de História - PUC-Rio

Prof. Otávio Leonídio Ribeiro Departamento de Arquitetura e Urbanismo - PUC-Rio

Prof ${ }^{a}$ Patrícia Leal Azevedo Corrêa Escola de Belas Artes - UFRJ

Prof $^{a}$ Elena Maria O'Neill Hughes Instituto de Artes - UERJ

Prof. Amaury Fernandes da Silva Junior Escola de Comunicação - UFRJ

Prof. Augusto César Pinheiro da Silva Vice-Decano de Pós-Graduação do Centro de Ciências Sociais - PUC-Rio

Rio de Janeiro, 20 de março de 2018 
Todos os direitos reservados. É proibida a reprodução total ou parcial do trabalho sem autorização da universidade, da autora e do orientador.

\section{Andreza de Lima Ribeiro Teixeira}

Mestre em Comunicação Social pela Pontifícia Universidade Católica (PUC-Rio) em 2011, especialista em Comunicação e Imagem pela PUC-Rio em 2008 e MBA em Comunicação e Marketing pela Escola Superior de Propaganda e Marketing (ESPM) em 2004. Graduada em Comunicação Social, habilitação em Jornalismo, pela Universidade Gama Filho (UGF) em 1990. Jornalista concursada da Universidade Federal do Rio de Janeiro, desempenha diversas atividades relativas à Comunicação e ao Jornalismo.

Ficha Catalográfica

Teixeira, Andreza de Lima Ribeiro

Degas e a fotografia : a (re)invenção do olhar / Andreza de Lima Ribeiro Teixeira ; orientador: Ronaldo Brito Fernandes. - 2018.

126 f. : il. color. ; $30 \mathrm{~cm}$

Tese (doutorado)-Pontifícia Universidade Católica do Rio de Janeiro, Departamento de História, 2018.

Inclui bibliografia

1. História - Teses. 2. História Social da Cultura - Teses. 3. Degas.

4. Arte. 5. Fotografia. 6. Impressionismo. I. Fernandes, Ronaldo Brito. II. Pontifícia Universidade Católica do Rio de Janeiro. Departamento de História. III. Título. 


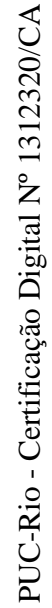

Para você. 


\section{Agradecimentos}

A Deus.

Ao Ronaldo, orientador mais do que querido.

Ao meu filho Fellipe.

A Edna, secretária mais do que especial.

Aos que de alguma forma me incentivaram a permanecer nesta jornada.

Obrigada. Consegui. 


\section{Resumo}

Teixeira, Andreza de Lima Ribeiro; Fernandes, Ronaldo Brito. Degas e a fotografia: a (re)invenção do olhar. Rio de Janeiro, 2018. 126p. Tese de Doutorado - Departamento de História, Pontifícia Universidade Católica do Rio de Janeiro.

Esta tese procura investigar a riqueza de expressão, as potencialidades e a diversidade experimental de Edgard Degas, um dos grandes artistas da modernidade, período de transformações sociais e tecnológicas decisivas que atingiram o auge no final do século XIX, mudando os paradigmas e alterando os modos de ver e viver. Para tanto, o estudo perpassa algumas fases da sua obra a fim de abordar a diversidade e traçar um paralelo com as inovações trazidas pela fotografia.

\section{Palavras-chave}

Degas; Arte; Fotografia; Impressionismo. 


\section{Resumé}

Teixeira, Andreza de Lima Ribeiro; Fernandes, Ronaldo Brito (Directeur). Degas et la photographie: la (ré)invention du regard. Rio de Janeiro, 2018. 126p. Tese de Doutorado - Departamento de História, Pontifícia Universidade Católica do Rio de Janeiro.

Cette thèse cherche à explorer la richesse de l'expression, les potentialités et la diversité expérimentale d'Edgard Degas, I'un des grands artistes de la modernité. Une période de changements sociaux et technologiques décisifs qui ont atteint son apogée à la fin du XIXe siècle, changeant les paradigmes et les façons de voir et vivre. Pourtant, l'étude parcourt certaines phases de son travail afin d'aborder la diversité et de faire le parallèle avec les innovations apportées par la photographie.

\section{Mots-clés}

Degas; Art; Photografie; Impressionnisme. 


\section{Sumário}

1. Introdução

2. Degas

2.1. Impressões

24

2.2. Caminhos

3. Conversas 39

3.1. A mão e o olho

3.2. Paris e a fotografia

54

4. Flânerie

63

4.1. Olhares

75

4.2. Movimento

79

5. Composições

90

5.1. Imagem

97

5.2. Estratégias

108

6. Conclusão

119

7. Referências bibliográficas 


\section{Lista de figuras}

$\begin{array}{lr}\text { Figura } 1 \text { - La baigneuse, } 1814 & 17\end{array}$

Figura 2 - La Libert guidant le peuple, $1830 \quad 19$

Figura 3 - Petites filles spartiates provoquant

$\begin{array}{ll}\text { des garçons, } 1860-1862 & 21\end{array}$

Figura 4 - Scène de guerra au Moyen Age,

dit à tort: Des malheurs de la ville d'Orléans, 1865

Figura 5 - Le bureau de coton à la Nouvelle-Orléans, 1873

Figura 6 - L’interiéur (Le viol), 1868-1869 30

Figura 7 - Femmes à la terrasse d'un café le soir, 1877

Figura 8 - Le petite danseuse, 1879-1881 35

Figura 9 - Grande arabesque, troisième temps,

$\begin{array}{ll}\text { première étude, 1892-1896 } & 37\end{array}$

Figura 10 - Le tub, 1888-1889 38

Figura 11 - Joseph Nicéphore Niépce,

Point de vue du Gras, 1827

Figura 12 - Louis Daguerre, Boulevard du Temple, 1838

Figura 13 - Daguerreótipo de Isadora Noe Freeman

and Mary Christiana Freeman, 1859

Figura 14 - Protótipo do estojo para fotografias de

daguerreótipo usado na França

Figura 15 - Eugène Atget, Maison à Versailles, 1921

Figura 16 - Eugène Atget, Quai de la Tournelle, 1911

Figura 17 - La Place de la Concorde, $1876 \quad 77$

Figura 18 - L’Absinthe (Au cafe), 1875-1876 78 
Figura 19 - Eadweard Muybridge, Jumping a hurdle,

black horse, 1887

Figura 20 - Aux courses en province, la voiture

en course, 1872

Figura 21 - Chevaux de courses devant les tribunes, 186988

Figura 22 - Édouard Manet, Les Courses À Longchamp, 1866

Figura 23 - August Sander, Notary, 1924

Figura 24 - August Sander, Young farmers, 1914

Figura 25 - Jeune femme se séchant après le bain, 1896

Figura 26 - Claude Monet, La Cathédrale de Rouen, 1894

Figura 27 - Claude Monet, La Cathédrale de Rouen:

Le Portail (Effet du matin), 1894

Figura 28 - La femme aux chrysanthèmes, 1865

Figura 29 - La famille Bellelli, 1858-1860 112

Figura 30 - Le foyer de la danse à l'Opéra

de la rue Le Peletier, 1872

Figura 31 - Examen de danse, $1874 \quad 116$

Figura 32 - Le Café-concert aux ambassadeurs, 1876-1877 118 
Observar é, em grande parte, imaginar o que esperamos ver.

Paul Valéry, Degas dança desenho 